\title{
Dynamics of Serine-8 Side-chain in Amyloid- $\beta$ fibrils and Fluorenylmethyloxycarbonyl Serine Amino Acid, Investigated by Solid-State Deuteron NMR
}

Liliya Vugmeyster ${ }^{\dagger}, *$, Dan Fai Au ${ }^{\dagger}$, Dmitry Ostrovsky ${ }^{\ddagger}$, Dillon Rickertsen ${ }^{\dagger}$, Scott M. Reed ${ }^{\dagger}$

$\dagger$ Department of Chemistry, University of Colorado Denver, Denver CO USA 80204

$\ddagger$ Department of Mathematics, University of Colorado Denver, Denver CO USA 80204

*To whom correspondence should be addressed: 1201 Larimer Street, Denver CO 80204, USA email: LILIYA.VUGMEYSTER@UCDENVER.EDU

\section{S1. Synthetic procedures for preparation FMOC-serine-Trt-d . $^{\text {. }}$}

A

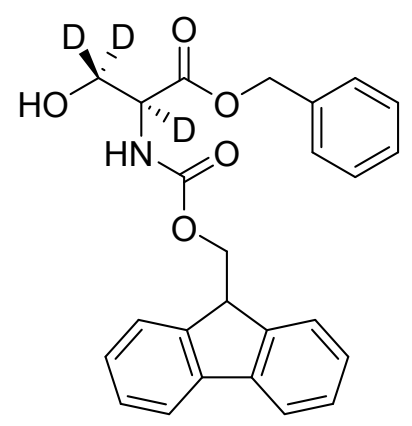

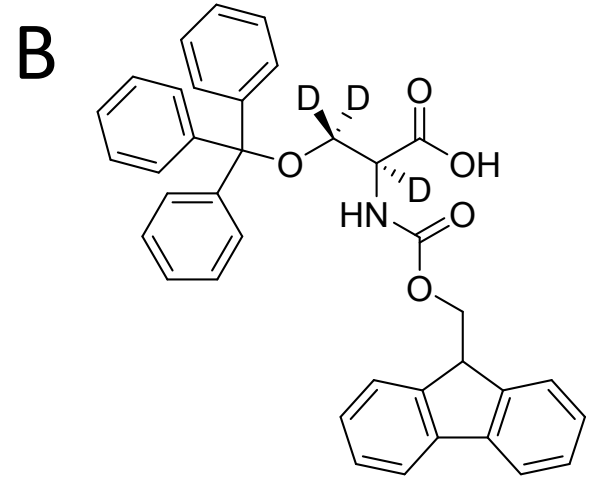

Figure S1. Structures of A) Benzyl (((9H-fluoren-9-yl)methoxy)carbonyl)-L-serinate-2,3,3- $d_{3}$ and B) $N$ (((9H-fluoren-9-yl)methoxy)carbonyl)-O-trityl-L-serine-2,3,3-d .

Benzyl (((9H-fluoren-9-yl)methoxy)carbonyl)-L-serinate-2,3,3- $d_{3}$ (Figure S1A): A round bottom flask $(25 \mathrm{~mL})$ was charged with DMSO (4 mL) and a magnetic stir bar. Fmoc-L-Serine-2,3,3- $d_{3}(505 \mathrm{mg}, 1.53$ mmol) was added to the round bottom flask and stirred until dissolved. DIPEA ( 2 equiv) was added in one portion followed by benzyl bromide (1.5 equiv). The solution was left to stir at room temperature for 19 hours and quenched with DI water $(10 \mathrm{ml})$. After quenching the reaction flask was cooled at $0{ }^{\circ} \mathrm{C}$ for 15 minutes. The water/DMSO was decanted and ethyl acetate $(20 \mathrm{~mL})$ was added. The ethyl acetate was washed with DI water $(3 \times 20 \mathrm{ml})$. The ethyl acetate was then washed with sat. ammonium chloride $(2 \times$ $30 \mathrm{~mL})$, sat. sodium bicarbonate $(3 \times 30 \mathrm{~mL})$, brine $(30 \mathrm{~mL})$, and DI water $(5 \times 30 \mathrm{~mL})$. The organic layer was dried over magnesium sulfate and ethyl acetate was removed via vacuum yielding a yellow oil. Yellow oil was triturated with hexane yielding a yellow solid, $542 \mathrm{mg}$ (1.29 mmol, 84.3\%).

${ }^{1} \mathbf{H}$ NMR $\left(\mathrm{CDCl}_{3}, 400 \mathrm{MHz}\right) \delta 7.77(\mathrm{~d}, J=7.5 \mathrm{~Hz}, 2 \mathrm{H}), 7.62(\mathrm{~d}, J=7.1 \mathrm{~Hz}, 2 \mathrm{H}), 7.58-7.25(\mathrm{~m}, 13 \mathrm{H})$, $5.74(\mathrm{~s}, 1 \mathrm{H}), 5.18(\mathrm{~s}, 2 \mathrm{H}), 4.43(\mathrm{~d}, J=6.4 \mathrm{~Hz}, 2 \mathrm{H}), 4.22(\mathrm{t}, J=6.4 \mathrm{~Hz}, 1 \mathrm{H}), 2.39(\mathrm{~s}, 1 \mathrm{H})$.

${ }^{13} \mathbf{C ~ N M R}\left(\mathrm{CDCl}_{3}, 100 \mathrm{MHz}\right) \delta 170.4,156.2,143.7,141.3,135.2,128.7,128.5,128.2,127.7,127.1$, $125.1,67.5,67.2,47.2 \mathrm{ppm}$. 
$\boldsymbol{N}$-(((9H-fluoren-9-yl)methoxy)carbonyl)-O-trityl-L-serine-2,3,3- $\boldsymbol{d}_{\mathbf{3}}$ : A round bottom $(25 \mathrm{~mL})$ was charged with a stir bar and 1. DCM $(5 \mathrm{~mL})$ was added and the solution was stirred until dissolved. After complete dissolution DIPEA (2 equiv.) was added and the reaction was left to reflux until completion as indicated by TLC. DCM $(11 \mathrm{~mL})$ was added and this organic layer was washed with DI water $(20 \mathrm{~mL})$ followed by brine $(2 \times 20 \mathrm{~mL})$. The organic layer was dried over magnesium sulfate and the solvent was removed via vacuum yielding a crude yellow oil.

A 2 neck round bottom flask $(100 \mathrm{~mL})$ was charged with a stir bar was flushed with nitrogen gas. $\mathrm{Pd} / \mathrm{C}$ $(10 \%)$ was added followed by ethyl acetate $(1 \mathrm{~mL})$. The crude yellow oil was transferred to the round bottom without further purification. Ethyl acetate $(7 \mathrm{~mL})$ was added followed by ethanol $(7 \mathrm{~mL})$. The round bottom was back filled with hydrogen gas 3 times and the reaction was left to stir at room temperature under a hydrogen atmosphere until completion as indicated by TLC. The round bottom was back filled with nitrogen gas and vacuum filtered over Celite. The filtrate was collected and the solvent was removed via vacuum yielding a crude orange oil. The crude orange oil was purified by flash chromatography using a gradient of methanol in $\operatorname{DCM}(0 \%, 25 \%$, to $100 \%)$ yielding a yellow solid $256 \mathrm{mg}(0.45 \mathrm{mmol}, 34.9 \%$ over two steps).

${ }^{1} \mathbf{H}$ NMR $\left(\mathrm{CD}_{3} \mathrm{COCD}_{3}, 400 \mathrm{MHz}\right) \delta 7.88(\mathrm{~d}, J=6.0 \mathrm{~Hz}, 2 \mathrm{H}), 7.52(\mathrm{dd}, J=6.0 \mathrm{~Hz}, 7.5 \mathrm{~Hz}, 2 \mathrm{H}), 7.50-7.27$ $(\mathrm{m}, 23 \mathrm{H}), 6.80(\mathrm{~s}, 1 \mathrm{H}), 4.38-4.25(\mathrm{~m}, 3 \mathrm{H})$

${ }^{13} \mathrm{C}$ NMR $\left(\mathrm{CD}_{3} \mathrm{COCD}_{3}, 100 \mathrm{MHz}\right) \delta 171.7,156.7,144.9,144.6,141.9,129.4,128.5,128.4,127.8,126.1$, $120.7,87.3,67.4,47.9 \mathrm{ppm}$ 

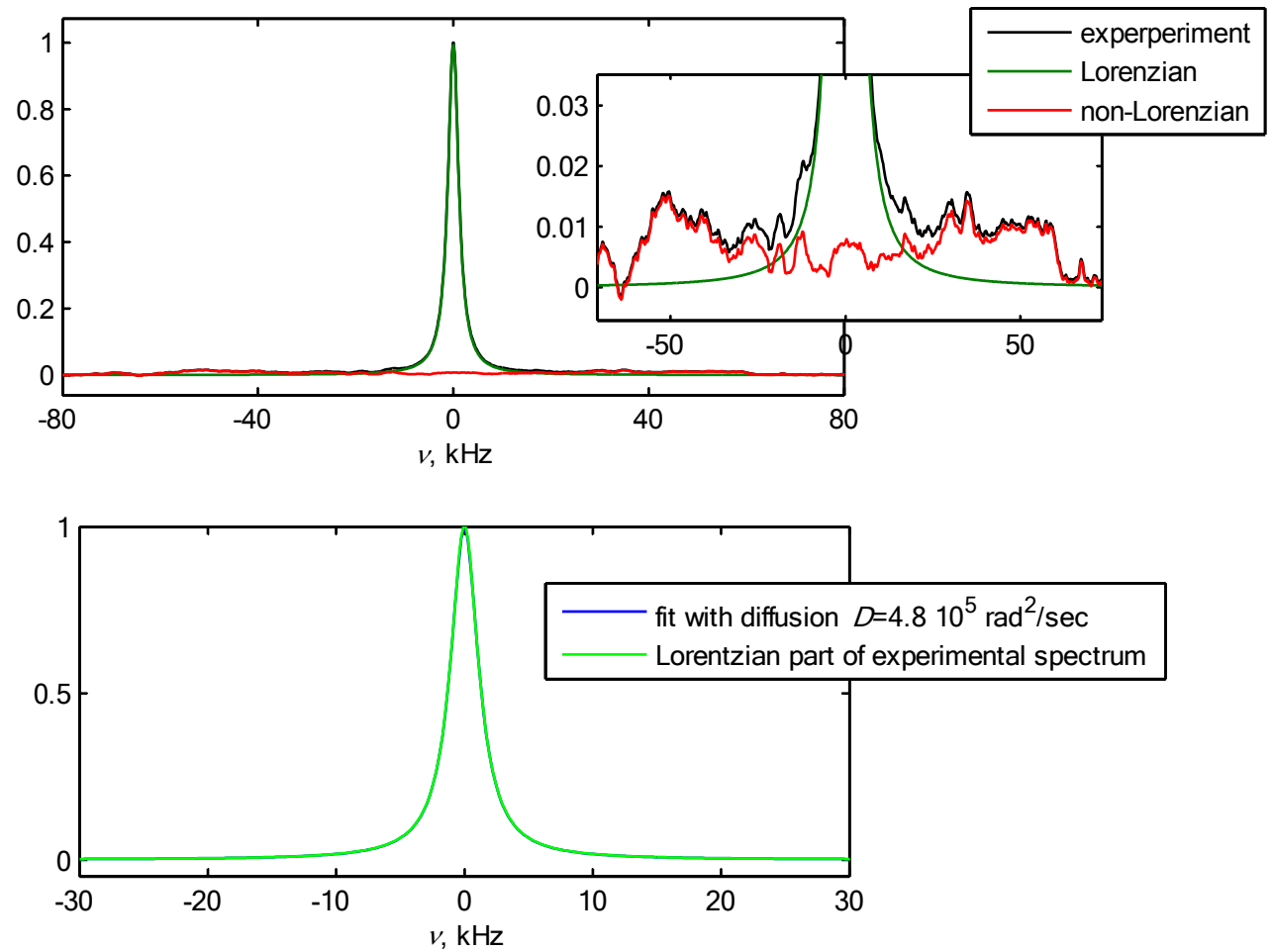

Figure S2. A) Decomposition of the experimental spectrum of the hydrated $A \beta_{1-40}$ fibrils labeled at the $S 8$ site at $310 \mathrm{~K}$ (black) into the Lorenzian (green) and non-Lorenzian (red) components. The former is attributed to the free state and the latter to the bound state and yield about $22 \%$ of the total intensity. B) The fit of the Lorenzian component to the isotropic diffusion model according to the approach detailed in reference ${ }^{1}$ and its supporting information. The best fit is obtained with the diffusion coefficient of $4.8 \cdot 10^{5}$ $\mathrm{rad}^{2} / \mathrm{sec}$ with the use of an additional $1.5 \mathrm{kHz}$ exponential line broadening to account for inhomogeneous dipolar interactions contribution to the linewidth, ${ }^{2}$ in analogy to the approach used for other residues in the $\mathrm{N}$-terminal domain of the fibrils. 


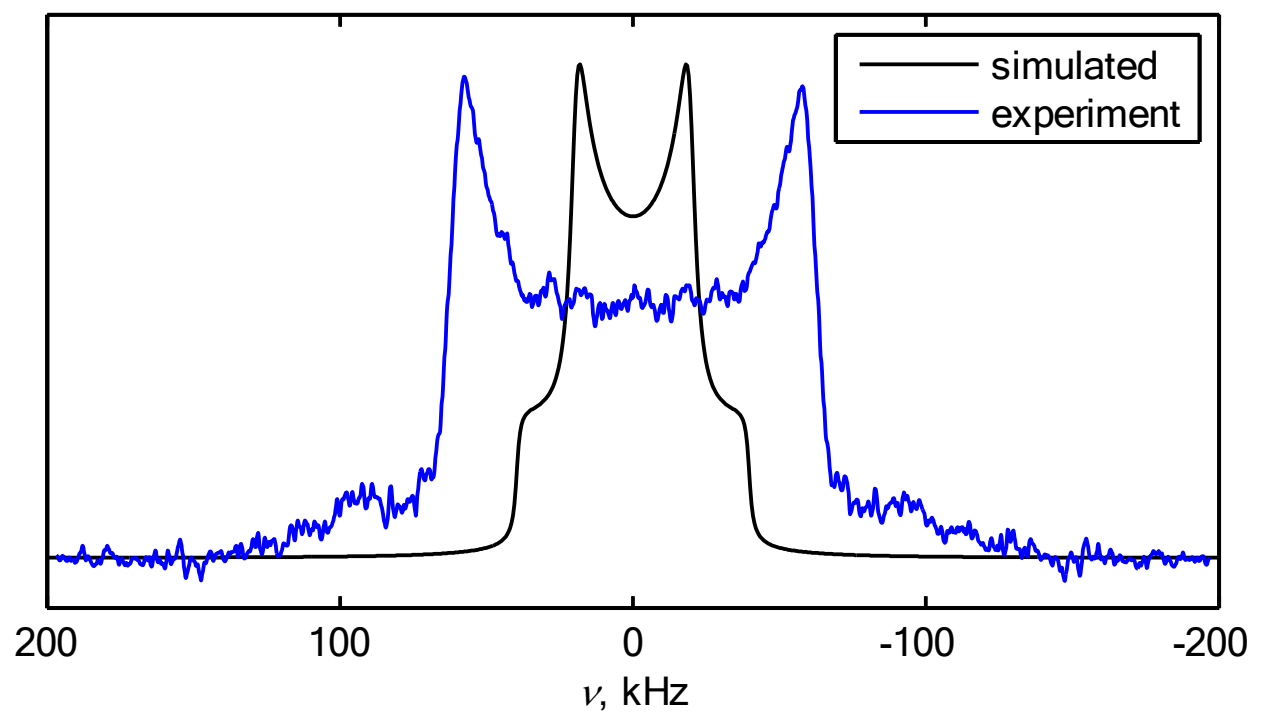

Figure S3. Simulated spectrum (black) corresponding to the 3 -site jumps mode with $k^{3 \text {-site }}=4.4 \cdot 10^{6} \mathrm{~s}^{-1}$ and equal rotameric populations (i.e. $\Delta E=0$ ). This rate constant matches the experimental value of $T_{1}$ for Fmoc-serine $(0.3 \mathrm{~s})$ at the highest experimental temperature of $330 \mathrm{~K}$ but yields a motionally narrowed spectrum in disagreement with the experimentally observed rigid pattern (blue).

\section{References}

(1) Au, D. F.; Ostrovsky, D.; Fu, R. and Vugmeyster, L. Solid-State NMR Reveals a Comprehensive View of the Dynamics of the Flexible, Disordered N-Terminal Domain of Amyloid-B Fibrils J. Biol. Chem. 2019, 294, 5840-5853.

(2) Hirschinger, J.; Miura, H.; Gardner, K. H. and English, A. D. Segmental Dynamics in the Crystalline Phase of Nylon-66 - Solid-State H-2 NMR Macromol. 1990, 23, 2153-2169. 